\title{
Freiras em movimentos de resistência às ditaduras militares na América Latina
}

\author{
Nuns in resistance movements against military dictatorships in Latin \\ America
}

Caroline Jaques Cubas ${ }^{1}$

\begin{abstract}
Resumo
O objetivo deste artigo é apresentar uma análise da presença e participação de religiosas católicas em movimentos de cunho político-social que, de alguma maneira, poderiam ser classificados como resistentes ou opositores às ditaduras militares no contexto latinoamericano. A observação da participação de freiras nestes movimentos, além de preencher um vazio historiográfico no que se refere às questões político-sociais da vida religiosa feminina na segunda metade do século XX, possibilita um redimensionamento das relações entre Igreja e ditaduras. Quanto a fontes, este artigo está ancorado especialmente em periódicos, inquéritos policiais e documentos diversos e no acervo da Bibliothèque de Documentation Internationale Contemporaine.
\end{abstract}

Palavras-chave: Ditaduras; Igreja Católica; freiras.

\section{Resumé}

L'objectif de cet article est de présenter une analyse de la présence et de la participation des religieuses catholiques dans les mouvements de nature politique et sociale qui, en quelque sorte, pourraient être classés comme résistants ou d'opposition aux dictatures militaires dans le contexte latino-américain. Observer la participation de religieuses dans ces mouvements, combler un vide historiographique en ce qui concerne les questions politiques et sociales des femmes religieuses dans la seconde moitié du XXe siècle, permet de donner une nouvelle mesure aux relations entre l'Église et les dictatures. Comme sources, cet article s'est ancré en particulier sur les périodiques, les enquêtes de police et divers documents obtenus à partir des fichiers du projet "Memórias Reveladas" et la collection de la Bibliothèque de Documentation Internationale Contemporaine.

Mots-clé: Dictatures; Église Catholique; religieuses.

Artigo recebido em: 21 de janeiro de 2015

\footnotetext{
${ }^{1}$ Doutora em história pela Universidade Federal de Santa Catarina. Professora do Departamento de história da Universidade do estado de Santa Catarina. Este artigo é uma versão sintetizada do capítulo 4 da tese "Do hábito ao ato: vida religiosa feminina ativa no Brasil (1960-1985)", defendida na Universidade Federal de santa Catarina em 2014. Esta pesquisa contou com o auxílio da Capes em sua etapa final. Email para contato: caroljcubas@gmail.com
}

\section{GANPHLAC}

Revista Eletrônica da ANPHLAC, ISSN 1679-1061, №. 18, p. 139-161, jan./jul. 2015. http://revista.anphlac.org.br/ 
Artigo aprovado para publicação em: 15 de março de 2015

Cala-se por vários motivos. Silêncio outorgado ou descomprometido. Omissão consciente ou inconsciência das possibilidades de fala. Cala-se por medo, incerteza, insegurança, vontade ou falta dela. Por voto, confiança ou fé. Por opressão ou decisão. Cala-se, e só. Este, porém, não é um trabalho sobre o silêncio. Antes, trataremos de mulheres que, apesar de seus espaços sociais bastante restritivos, buscaram diferentes formas de dizer.

Ainda que as relações entre Igreja Católica e ditaduras militares sejam relativamente bem exploradas pela historiografia contemporânea, as reflexões tratam geralmente da participação de religiosos homens na oposição ou colaboração aos regimes militares. Tal constatação pode ser compreendida na medida em que, efetivamente, são os homens os únicos autorizados a falar publicamente em nome da Igreja enquanto instituição. A hierarquia católica é construída apenas com a participação dos membros homens, e são estes, portanto, que têm a possibilidade de definir ações e posicionamentos oficiais. Sabemos, porém, que a Igreja Católica é formada não apenas por seu corpo hierárquico, mas por um grande número de religiosos, religiosas e fiéis, o que nos obriga a percebê-la como uma instituição bastante heterogênea, marcada por conflitos e contravenções.

Buscando atentar em possibilidades de ação destes membros cuja atuação escapa, por vezes, às determinações oficiais, apresentamos por meio deste artigo uma reflexão sobre a atuação de religiosas consagradas católicas na resistência ${ }^{2}$ às ditaduras militares na América Latina, mais especificamente, na Argentina. Essa resistência, ainda pouco quantificada e registrada, pode ser percebida especialmente por engajamentos político-sociais e luta pelos direitos humanos. Como os governos repressivos não foram casos isolados, este trabalho propõe, em um primeiro momento, uma observação de

\footnotetext{
${ }^{2}$ Em relação ao conceito de resistência, é importante pontuar que não nos referimos aqui exclusivamente à resistência armada, mas adotamos uma noção mais abrangente e complexa. Partilhamos, em primeiro lugar, do que foi indicado por Michel Foucault (1988, p. 91), segundo o qual toda relação de poder traz consigo uma ação de resistência. A forma de pensar a resistência adotada neste trabalho é também tributária dos inúmeros projetos dedicados à reflexão sobre o tema durante o período da ocupação nazista, especialmente na França. Jacques Semelin (2013), antes mesmo de considerar as evidentes especificidades contextuais, ressalta a necessidade de romper com uma noção de resistência, que usualmente destaca e heroiciza atos e atores. Em lugar desse entendimento restrito, sugere acentuar a importância de uma resistência do cotidiano e do papel daqueles que, muitas vezes, permaneciam no anonimato.
}

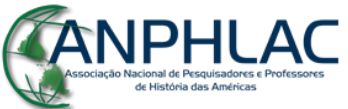

Revista Eletrônica da ANPHLAC, ISSN 1679-1061, N. 18, p. 139-161, jan./jul. 2015. http://revista.anphlac.org.br/ 
ocorrências gerais para, em seguida, dedicar-se exclusivamente ao caso das freiras francesas Alice Domon e Léonie Duquet, desaparecidas durante a ditadura argentina. A escolha deste caso justifica-se pelo espaço a ele dedicado em jornais e revistas e, além disso, por ser representativo das possibilidades de ação perpetradas por mulheres religiosas que se voltaram contra regimes repressivos.

\section{Igreja Católica, freiras e ditaduras}

O papel assumido pela Igreja Católica durante as ditaduras militares na América Latina é bastante peculiar; afinal, apesar de um reconhecido alinhamento à resistência por meio da luta pelos direitos humanos e contra a tortura em países como o Brasil e o Chile, tal posicionamento não pode ser generalizado como representativo da Igreja Católica latino-americana na segunda metade do século XX. Na Argentina, o posicionamento oficialmente conivente por parte dos bispos, em relação ao regime instituído em 1976, teria sido respaldado por uma tentativa de manutenção da "civilização cristã e ocidental" (MIGNONE, 2006, p.49). Conivência semelhante pôde ser também observada no Paraguai do general Alfredo Stroessner. No Chile, por outro lado, as boas relações que a Igreja mantinha com o governo de Allende engendraram uma forte desconfiança e fizeram, entre outros motivos, com que as relações estabelecidas com a ditadura de Pinochet fossem marcadas por animosidades desde o princípio, as quais podem ser observadas pelas ações instauradas pela Vicaria de la Solidaridad. O caso brasileiro também merece destaque, já que observamos uma alteração de posicionamentos. Se em 1964 a Igreja se colocou ao lado do movimento militar, em nome das chamadas reformas conservadoras materializadas nas reivindicações da "Marcha da Família com Deus pela Liberdade", a partir de 1968 observamos uma alteração deste posicionamento oficial e um gradual alinhamento à resistência, com a luta pelos direitos humanos e contra as torturas.

É importante pontuar, todavia, que, para além destes posicionamentos oficiais, a Igreja Católica deve ser compreendida em sua heterogeneidade, uma vez que os posicionamentos oficiais não significam a concordância por parte de todos seus membros. Em toda a América Latina é possível observar a ação de homens e mulheres, padres, bispos

\section{GANPHLAC}

Revista Eletrônica da ANPHLAC, ISSN 1679-1061, №. 18, p. 139-161, jan./jul. 2015. http://revista.anphlac.org.br/ 
e freiras, que contrariaram instruções oficiais em nome daquilo que acreditavam ser correto, justo e verdadeiro.

Apesar da noção trivial de obediência e abnegação que caracteriza a opção pela vida religiosa consagrada, impunham-se conflitos e escolhas. Além do conturbado momento político e social que assolava os países da América Latina, a própria Igreja Católica passava por um processo de reformulação institucional, oficializada pelo Concílio Vaticano II no início da década de 60, o qual definia diferentes parâmetros de vida religiosa, a partir de então direcionada à atuação junto à sociedade. Entre as formas de atuação, situamos a vida em inserção que, de forma genérica, consistia em abandonar os muros dos conventos e viver em pequenas comunidades, em contato direto com o povo. Essa proposta, porém, não obteve aceitação unânime ou absolutamente pacífica. Muitos religiosos e religiosas optavam pela Igreja justamente pelo afastamento que ela proporcionava em relação àquilo que poderia ser considerado mundano. Assistiu-se, naquele período, a um grande conflito entre aqueles considerados tradicionais, que olhavam as propostas do Concílio com desconfiança, e os progressistas, que assumiam as possibilidades de engajamento social como legítimas e necessárias (SERBIN, 2008, p. 175).

Apesar das desavenças, um considerável número de religiosas assumiu a vida inserida e o trabalho em comunidades. Segundo Maria José Rosado Nunes (1986, p. 504), referindo-se às Comunidades Eclesiais de Base no Brasil, as CEBs, "as religiosas foram não somente as mais numerosas [...], mas também, a qualquer outro fator que se possa comparálas, as mais eficazes no estabelecimento de comunidades nos bairros pobres das cidades". Essa nova forma de vivenciar a vida religiosa, por atuação nas pequenas comunidades inseridas e nas CEBs, tornou muito mais nítidas as desigualdades sociais, de classe e gênero. Nesse sentido, iniciaram-se trabalhos de conscientização no interior dessas comunidades. De acordo com Cristina Aparecida Brolhani (2003), as CEBs tiveram um papel de destaque nos movimentos sociais de base como participantes da luta contra a ditadura e pela abertura política no Brasil. Neste sentido, Michael Lowy (2000, p.12) afirma que "um setor significativo da Igreja - tanto fiéis, como clero - na América Latina, mudou de posição na área de lutas sociais, passando, com seus recursos materiais e espirituais, para o lado dos pobres e de sua luta por uma sociedade nova".

\section{GANPHLAC}

Revista Eletrônica da ANPHLAC, ISSN 1679-1061, №. 18, p. 139-161, jan./jul. 2015. http://revista.anphlac.org.br/ 
Conforme dito anteriormente, existem inúmeras referências às relações entre a Igreja e os governos militares, sejam elas de embate ou colaboração, nos periódicos de época e em trabalhos de pesquisa que tomam essa relação como objeto. Essas referências citam a importância da participação de padres seculares, bispos, religiosos e religiosas nas lutas pelos direitos humanos, contra a prática das torturas, e nas reivindicações do paradeiro de desaparecidos políticos. Em relação às religiosas, porém, raramente encontramos uma reflexão que demonstre consistentemente como foi essa participação. Ainda que sejam citadas, normalmente aparecem como coadjuvantes, sendo comum encontrarmos um hiato significativo a respeito de suas ações. São conhecidos casos como os de Dom Paulo Evaristo Arns, Dom Ivo Lorscheiter, Dom Pedro Casaldáglia, Dom Hélder Câmara (apelidado de "bispo vermelho"), Dom Marcelo Pinto Carvalheira (que sentiu no corpo a ação coerciva do regime militar), Frei Tito, Gabriel Longueville, Carlos de Dios Murias, Dom Enrique Angelelli, entre tantos outros. Sobre as religiosas, no entanto, faltam-nos os casos exemplares. Segundo o projeto "Brasil Nunca Mais", das 122 prisões de padres, bispos e religiosos que ocorreram entre 1968 e 1978, nove foram bispos, 84 sacerdotes, 13 seminaristas e irmãos e apenas seis irmãs (Folha de São Paulo, 23/01/1979, p. 05). Esses dados tornam-se bastante curiosos quando sabemos que as religiosas tiveram participação massiva nas CEBs, organizando grupos de reflexão e conscientização. Ora, se esses podem ser considerados movimentos sociais de embate ao contexto político da época, como considerar a participação das irmãs senão como igualmente combativas? Acreditamos, dessa forma, que as ações de resistência por parte das religiosas transcendem os números publicados.

Em pesquisas realizadas sobre a mesma temática no Brasil, encontramos, por meio de depoimentos e dos arquivos do projeto Memórias Reveladas, uma série de casos que nos ajudam a pensar a participação de religiosas no embate à ditadura militar brasileira. Neste artigo, porém, nos restringiremos a alguns casos para além das fronteiras nacionais. Para tanto, grande parte de nosso corpus documental foi consultado no acervo da Bibliothèque de Documentation Internationale Contemporaine, em que foi possível encontrar diferentes referências a respeito do envolvimento de freiras em movimentos de resistência, transgressão ou contestação aos regimes ditatoriais observados no contexto latino-americano durante a segunda metade do século XX. É certamente necessário

\section{GANPHLAC}

Revista Eletrônica da ANPHLAC, ISSN 1679-1061, №. 18, p. 139-161, jan./jul. 2015. http://revista.anphlac.org.br/ 
considerar as diferenças tanto no que diz respeito à organização dos regimes governamentais em diferentes países quanto ao próprio posicionamento das Igrejas em relação a esses regimes. Por outro lado, acreditamos na possibilidade de aproximações comparativas na medida em que os regimes autoritários aconteceram em uma temporalidade similar e a Igreja Latino-Americana, apesar das diferenças observadas, foi envolvida pelos direcionamentos propostos pelo Concílio Vaticano II e, especialmente, pelas conferências episcopais realizadas em Medellín e Puebla.

A história comparativa vem sendo bastante debatida, conforme pondera Benjamin Z. Kedar. Além de apresentá-la como uma perspectiva, e não como um método, Kedar (2009, p. 1-35) referencia diversos historiadores e pesquisadores que, com seus estudos, possibilitam a reflexão sobre os limites e possibilidades dessa perspectiva aplicada ao trabalho historiográfico. Segundo Cristina Scheibe Wolff e Joana Maria Pedro, na opção pela abordagem comparativa a respeito das ditaduras

\begin{abstract}
Os países são próximos geograficamente, viveram num mesmo período governos ditatoriais e reagiram a eles das mais diversas maneiras, num momento em que ao nível internacional as pessoas estavam discutindo mudanças culturais intensas que envolviam revolução sexual e feminismos. É para buscar a especificidade destas configurações, que não são isoladas, ao contrário, se cruzam, que a perspectiva da história comparada e da história cruzada é utilizada (PEDRO, WOLFF, 2011, p. 43).
\end{abstract}

Observa-se que, além da adoção de um olhar comparativo que busque as singularidades e diferenças, as autoras sugerem transcender a noção da comparação e adotá-la conjuntamente com a proposta de uma história cruzada, a qual possibilita analisar a questão estudada como uma rede de relações, enfatizando-se a construção de sentidos a respeito dos aspectos analisados. Essa noção propõe, entre outros aspectos, observar o processo de interação que, de forma dinâmica, afeta e modifica os elementos que interagem. Para Werner e Zimmermann (2003, p.08), a história cruzada está muitas vezes relacionada, em escala nacional, às formações sociais, culturais e políticas com que se assume ter ligações.

A atuação das religiosas em movimentos de resistência e contestação aos governos militares pode ser, assim, analisada de forma mais ampla. Isto porque, apesar das especificidades de cada país ao longo das décadas de 50 a 80 , as fronteiras nacionais não

\title{
GANPHLAC
}

Revista Eletrônica da ANPHLAC, ISSN 1679-1061, №. 18, p. 139-161, jan./jul. 2015. http://revista.anphlac.org.br/ 
limitavam a atuação da Igreja Católica. Vários países da América Latina estavam sob o jugo de governos autoritários e, além disso, a aliança conhecida como Operação Condor coordenava, juntamente aos EUA, ações de repressão àqueles que manifestavam resistência às ditaduras latino-americanas. Tais elementos de comparação fundamentam-se também em Marc Bloch, segundo o qual, para a efetividade da comparação, dois aspectos são imprescindíveis: por um lado, similaridade de fatos, e, por outro, dessemelhanças nos ambientes em que essas similaridades ocorrem (BARROS, 2007).

O envolvimento de religiosos e religiosas com questões sociais não foi, certamente, particularidade de um só país. De acordo com Vivian Moretti e Priscila Sena (2011, p. 353) "as igrejas cristãs, particularmente a Católica na América Latina, em toda a sua trajetória, sempre se mostraram como uma força social significativa." Neste sentido, durante os regimes militares, "parte da força opositora ao governo foi influenciada por discursos cristãos." Em razão disso, vários foram os membros da Igreja submetidos às forças das repressões, por meio de prisões, banimentos, torturas e assassinatos ou desaparecimento.

Podemos referenciar, como exemplo, uma reunião de bispos e religiosos ocorrida em Riobamba - Equador, em 1976. ${ }^{3}$ Nesta, foram presos 17 bispos, 22 padres, cinco freiras (três equatorianas, uma holandesa e uma espanhola) e 12 laicos (dos quais, quatro eram mulheres). O objetivo do encontro - segundo carta enviada ao Vaticano e assinada pelos 17 bispos em questão - era a apresentação e troca das experiências pastorais na diocese de Riobamba, entre bispos presentes e representantes de diferentes países, e a realização de um diagnóstico sobre o momento pelo qual passava a América Latina. ${ }^{4}$ Segundo o documento, o encontro que acontecia fraternalmente desde o dia 9 de agosto, congregando participantes de diferentes países, foi abruptamente interrompido em 12 do mesmo mês por intervenção armada da parte do governo equatoriano. A justificativa apresentada pelo Ministério do Interior, ainda de acordo com o documento apresentado pelos bispos, era a necessidade de conhecer o tema da reunião, seguida da grave acusação de que se tratava

\footnotetext{
${ }^{3}$ O Equador foi governado por ditaduras militares entre 1972 e 1979. De 1972 a 1976, sob o comando do general Guilhermo Rodriguez Lara, e de 1976 a 1979, pelo triunvirato Alfredo Poveda (Marinha), Guilhermo Durán (Exército) e Luís Leoro (Aeronáutica).

${ }^{4}$ ALVEAR, Bispo Enrique (et alli.) Comuniqué au Vatican. Riobamba, 13/ 08/ 1976. BDIC - Bibliothèque de Documentation Internationale Contemporaine. Fundo Fdelta2118.
} 
efetivamente de um encontro subversivo. Além da prisão, a ação governamental resultou na expulsão dos religiosos estrangeiros que atuavam na região, fato que gerou forte comoção. O protesto expedido pela diocese de Riobamba em 13 de agosto posicionou-se publicamente contra a ingerência do governo nos assuntos da Igreja, contra a violação dos direitos do homem e contra a injúria feita à Igreja de Riobamba, na pessoa de seu bispo, e à Igreja Latino-Americana. ${ }^{5}$

Outro documento de denúncia, assinado pela Comissão terceiro-mundista da Igreja Católica, elenca ocorrências interpretadas como "uma luta sistemática contra a Igreja da América Latina." ${ }^{6} \mathrm{O}$ teor do documento é anunciado desde as primeiras linhas, na epígrafe retirada de uma declaração do Conselho Episcopal Chileno, em 17 de agosto de 1976:

\begin{abstract}
Os atos que nós denunciamos e condenamos não são atos isolados. Eles são fruto de um processo ou sistema com características perfeitamente definidas, que ameaçam se impor, sem contrapeso, em nossa América Latina. Sob o signo de uma referência constante e sem apelo à segurança nacional como justificativa, assistimos ao reforço progressivo de um modelo de sociedade que sufoca as liberdades fundamentais, viola os direitos mais elementares e submete os cidadãos aos grilhões de um estado policial temível e onipresente. ${ }^{7}$
\end{abstract}

Após uma breve introdução na qual apresenta questões gerais sobre o posicionamento da Igreja Católica em relação aos governos militares na América Latina, o documento descreve uma série de casos ocorridos entre 1975 e 1976, considerados suficientemente representativos das lutas e repressões enfrentadas pela Igreja. Destes, três envolvem diretamente a participação de religiosas: na Bolívia, em setembro de 1975, três religiosas espanholas foram presas e expatriadas sob a acusação de terem participado dos preparativos de uma reunião de trabalhadores. Tal ato foi então interpretado como ingerência nas questões políticas do país. No Chile, em outubro de 1975, religiosas, padres

\footnotetext{
${ }^{5}$ Ibid.

${ }^{6}$ Commission Tiers-monde de l'Église Catholique. Une lutte systématique contre l'Eglise d'Amérique Latine. BDIC - Bibliothèque de Documentation Internationale Contemporaine. Fundo Dial. Nanterre, França.

${ }^{7}$ Ibid. p.01. "Les actes que nous dénonçons et condamnons ne sont pas des actes isolés. Ils sont le fruit d'un processus ou système aux caractéristiques parfaitement définies, qui menace de s'imposer, sans contrepoids, dans notre Amérique latine. Sous le signe d'une référence constante et sans appel à la sécurité nationale comme justification, on assiste au renforcement progressif d'un modèle de société qui étouffe les libertés fondamentales, viole les droites les plus élémentaires et soumet les citoyens au carcan d'un état policier redoutable et omniprésent." (tradução nossa)
}

\title{
GANPHLAC
}

Revista Eletrônica da ANPHLAC, ISSN 1679-1061, №. 18, p. 139-161, jan./jul. 2015. http://revista.anphlac.org.br/ 
e laicos foram presos em Santiago, acusados de dar asilo e auxílio a membros clandestinos vinculados ao Movimento de Esquerda Revolucionária - MIR. Na Argentina, em julho de 1976, os corpos de três religiosas assassinadas por balas foram descobertos nas dependências da Igreja de Pompeya, ao sul de Buenos Aires. ${ }^{8}$

O envolvimento de religiosas na contraposição aos regimes militares, na luta por melhores condições sociais ou em defesa dos direitos humanos na América Latina, recebeu também a atenção dos periódicos brasileiros, ainda que timidamente. Em 23 de janeiro de 1968, o Diário de Notícias publica, em matéria de capa, a seguinte manchete: "Freira é quem conseguia armas para guerrilheiros", referindo-se às ações de uma freira norteamericana na Guatemala (Diário de Notícias, 23/01/1968, Capa). No corpo da reportagem, a irmã Mary Peter, 39 anos, é apresentada como a líder de um grupo de missionários, composto por mais cinco padres e quatro freiras, supostamente envolvidos com guerrilheiros fidelistas, cujo objetivo seria facilitar o contrabando de armas (Diário de Notícias, 23/01/1968, p.09). Em 02 de agosto de 1974, a Folha de São Paulo publicou breve reportagem noticiando a explosão de uma bomba na casa habitada por cinco freiras consideradas de esquerda (Folha de São Paulo, 02/08/1974, p. 05). Ainda que em 1974 a Argentina não estivesse sob o jugo da Junta Militar, a qual assume o governo em 1976, a nota vem ao encontro de nosso interesse, posto que as freiras que sofreram o atentado eram membros do Movimento de Sacerdotes para o Terceiro Mundo, de orientação esquerdista.

Em extensa e substanciosa pesquisa sobre o catolicismo tercermundista ${ }^{9}$ na Argentina, Claudia Touris aborda a trajetória de religiosas que acabaram por se envolver,

\footnotetext{
${ }^{8} \mathrm{~A}$ respeito da última ocorrência, o documento referencia a publicação de um artigo no Le Monde Diplomatique de 6 de julho de 1976. No entanto, ao consultar o jornal, não encontramos a referida nota.

${ }^{9}$ A relação de religiosas com o Movimento de Sacerdotes para o Terceiro Mundo, na Argentina, foi consistentemente trabalhada por Claudia Touris, no sexto capítulo da tese Catolicismo y cultura política en la Argentina. Neste, a autora apresenta dados e constatações que ampliam a percepção acerca do envolvimento de religiosas com questões de cunho social e político para o contexto latino-americano. Touris faz apontamentos introdutórios acerca da vida religiosa feminina na Argentina durante o século XX que podem ser perfeitamente relacionados à situação da vida religiosa feminina no Brasil. Isso porque, apesar das diferenças nacionais e regionais, pensar o pertencimento à Igreja Católica impõe certas diretrizes institucionais. Um exemplo é a situação de submissão vivida pelas religiosas, especialmente no período que antecede o Concílio Vaticano II. O papel (não) desempenhado pelas mulheres na hierarquia da Igreja foi, ao longo dos séculos, justificado por argumentos teológicos, os quais praticamente impossibilitavam a reflexão histórica e, dessa forma, impediam a percepção da construção social das diferenças de gênero. Para além destes apontamentos, a proposta da autora é explorar as possibilidades da emergência de um setor terceiromundista entre as religiosas. Tal setor seria caracterizado, seguindo o modelo do Movimento de Sacerdotes pelo Terceiro Mundo - MSTM, pelo envolvimento com as causas sociais e políticas, alinhando-se às
}

\section{GANPHLAC}

Revista Eletrônica da ANPHLAC, ISSN 1679-1061, №. 18, p. 139-161, jan./jul. 2015. http://revista.anphlac.org.br/ 
de diferentes maneiras, com uma sorte de catolicismo social e engajado. Segundo a autora, ainda que as religiosas não tenham desenvolvido um "pensamento crítico organizado", tornaram-se importantes referências em questões não apenas religiosas, mas também sociopolíticas (TOURIS, 2009). Touris pondera que, em relação à Argentina - tal como observamos no Brasil - o interesse acadêmico a respeito da vida religiosa feminina é bastante restrito, e quando abordadas as religiosas aparecem marginalmente vinculadas às histórias eclesiásticas do período colonial (TOURIS, 2012). Ao pensar a apropriação deste catolicismo tercermundista e avaliar sua representatividade entre as religiosas, a autora percebe uma tensão no que diz respeito às possibilidades de participação das mulheres na esfera pública/política. Esta tensão é analisada a partir de uma perspectiva de gênero, a qual resulta, para Touris, da contraposição entre dois modelos femininos: Marianne e Maria.

La alusión a las figuras de Marianne y Maria pretende dar cuenta de la tensión irresuelta de los modelos femeninos asociados a la participación y el involucramiento en la esfera pública mediante la defensa de los valores de la libertad, la igualdad y la fraternidad, y a la mujer-madre espiritual, sumisa, casta y abnegada, respectivamente, que identificamos en el discurso y en las prácticas asumidas por algunas religiosas cercanas al tercermundismo (TOURIS, 2012, p. 299)

Partindo desta perspectiva, ao analisar as condições de possibilidades das experiências de religiosas tercermundistas, Touris (2012) destaca as significativas mudanças instituídas pelo Concílio Vaticano II na estruturação da vida religiosa feminina. Como exemplo apresenta, entre outras considerações, a trajetória da ex-religiosa María Teresa Dri, a qual pertenceu à Congregação de Nossa Senhora da Imaculada Conceição de Castres e se vinculou ao Movimento dos Sacerdotes Tercermundistas - MSTM. Tal vinculação trouxe-lhe uma série de problemas, os quais resultaram em sua saída da congregação e posterior vinculação aos montoneros. Outro caso bastante significativo é o

propostas conciliares e de Medellín, especialmente no que diz respeito à opção pelos pobres. Para tanto, Touris se dedica a publicações de experiências vivenciadas por freiras que assumiam a vida em inserção e, especialmente, ao depoimento de religiosas para, por meio desses recursos, perceber em que medida as ações das religiosas (apesar das ambivalências no que diz respeito à consciência política ou mesmo à possibilidade de romper com espaços sociais previamente determinados pela instituição à qual pertenciam) podem ser incorporadas ao que chama de constelação terceiro-mundista. Cf TOURIS, Claudia. Catolicismo y cultura politica en la Argentina. La "constelación tercermundista" (1955-1976). 2012. 463f. Tese (Doutorado em História). Facultad de Filosofia y Letras. Universidad de Buenos Aires.

\section{GANPHLAC}

Revista Eletrônica da ANPHLAC, ISSN 1679-1061, №. 18, p. 139-161, jan./jul. 2015. http://revista.anphlac.org.br/ 
da irmã Ester Sastre, da Congregação do Sagrado Coração, que também se dedicou a trabalhos pastorais considerados tercermundistas.

Também a respeito do caso Argentino, María Soledad Catoggio (2010) aborda a singularidade de trajetórias de religiosas durante a ditadura. Catoggio trabalha com o argumento de que a dupla condição "mulher" e "religiosa" trazia vantagens para fazer frente à repressão estatal. Analisa, nesse sentido, o repertório de estratégias agenciadas pelas religiosas. Em referência ao trabalho de Claudia Touris, Catoggio afirma que a observação de práticas engajadas entre as religiosas contrasta com a ausência de um discurso sobre essa prática. Dessa forma, o interesse pelas ações das religiosas pode ser compreendido pela disseminação de um estereótipo que trata as freiras como "mulheres enterradas em vida" (CATOGGIO, 2010, p. 30). Ao apresentar a trajetória de religiosas que, de alguma forma, se vincularam às questões políticas, Catoggio (2010, p. 40) propõe compreender esta política em termos de uma participação cidadã e de transformação social.

Assim como as autoras citadas acima, concordamos com a constatação de que o fato de não existir uma reflexão institucional (por parte das congregações religiosas femininas ou da CRB - Conferência dos Religiosos do Brasil) sistematizada a respeito do envolvimento de religiosas com movimentos de resistência e oposição às ditaduras militares não significa a inexistência desse envolvimento. É necessário observá-lo a partir dos espaços sociais comumente ocupados pelas próprias religiosas. Tais espaços, ao contrário do que ocorreu com bispos e sacerdotes que ocupavam púlpitos e se posicionavam publicamente, dizem respeito muito mais às esferas privadas, aos trabalhos sociais e aos espaços em que a participação efetiva de freiras não causaria estranhamento ou desconfiança, como educandários, asilos e hospitais. O caso de Alice Domon e Léonie Duquet, do qual trataremos a seguir, ilustra tais constatações.

\section{As freiras francesas}

A trajetória das freiras francesas Alice Domon e Léonie Duquet, assassinadas pela ditadura argentina em 1977, é particularmente interessante, pois ilustra que o engajamento social por parte de religiosas se imiscuía, muitas vezes, à resistência política. Apenas na Folha de São Paulo, entre 14 de dezembro de 1977 e 29 de março de 1978, contamos mais

\section{GANPHLAC}

Revista Eletrônica da ANPHLAC, ISSN 1679-1061, №. 18, p. 139-161, jan./jul. 2015. http://revista.anphlac.org.br/ 
de 13 reportagens dedicadas a acompanhar todos os trâmites do processo que causou uma verdadeira instabilidade nas relações diplomáticas entre França e Argentina. Além disso, a cobertura conferida ao caso no Brasil tornou-se bastante representativa do momento político atravessado pelo País, na medida em que tornar públicas as atrocidades do regime argentino, de alguma forma, valorizava a abertura lenta, gradual e segura anunciada pelo governo Geisel.

A primeira referência que encontramos ao caso das irmãs foi publicada na Folha de São Paulo sob a manchete "Governo Argentino promete anistia" (Folha de São Paulo, 14/12/1977, p. 09). A nota não diz respeito exclusivamente ao caso das irmãs, mas à promessa de anistia parcial, feita pelo governo argentino, para que os presos políticos que "souberam reabilitar-se e dar-se conta de seus erros cometidos contra a sociedade", segundo as palavras do ministro do Interior, general Albano Herguindeguy, pudessem passar as festividades de natal na casa de familiares. Após transcrever algumas declarações do presidente argentino Jorge Rafael Videla, a Folha descreve os protestos do governo francês contra as autoridades argentinas no caso de duas religiosas francesas, irmã Alicia e irmã Leonice (sic), sequestradas na semana anterior, pelo que presumia-se pertencerem a grupos civis armados. A justificativa, em princípio, era a proximidade que as irmãs mantinham com o grupo de mães que se reuniam quase que diariamente na Praça de Maio para reivindicar o paradeiro de seus filhos e que eram chamadas, pelas autoridades argentinas, de las locas.

No dia seguinte, a Folha de São Paulo volta a abordar o caso, porém sem muita ênfase, já que, além de brevíssima, a nota "França quer saber o paradeiro das freiras" divide espaço na página com inúmeros anúncios que promovem desde aparelhos para surdez até vitrolas Gradiente (Folha de São Paulo, 15/12/1977, p. 13). A diagramação sugere profunda ironia, pois, ao mesmo tempo que se promovem aparelhos auditivos, a pequena nota sobre o desaparecimento das freiras permanece um grito não ouvido. Ainda que tímida, a nota nos chama atenção por ressaltar novamente as questões diplomáticas, dada a presença do embaixador francês na chancelaria argentina. É curioso porém que, até aquele momento, as duas freiras francesas desaparecidas não tinham sido efetivamente personificadas nas reportagens, ou seja, sua importância era exclusivamente o fato de serem freiras, francesas e terem desaparecido. Os motivos do desaparecimento e a

\section{GANPHLAC}

Revista Eletrônica da ANPHLAC, ISSN 1679-1061, №. 18, p. 139-161, jan./jul. 2015. http://revista.anphlac.org.br/ 
trajetória das irmãs, além das suposições apresentadas na nota anterior, pareciam não merecer maiores atenções. Neste sentido, com o propósito de ampliarmos nossa reflexão a respeito das relações entre a vida religiosa feminina e as transformações políticas, sociais e culturais no contexto latino-americano, nos ateremos às trajetórias de Léonie Duquet e Alice Domon.

Alice Domon e Léonie Duquet chegaram à Argentina em momentos distintos. Léonie, em 1949, e Alice, em 1967 (GAMBETTA, 1979). Ambas, pertencentes à Congregação das Irmãs das Missões Estrangeiras, fundada em 22 de julho de 1931 pelo padre Albert Nassoy e pela irmã Maria Dolores Salazar, desenvolveram trabalhos pastorais ao lado de comunidades empobrecidas e campesinas. Antes dos trabalhos inseridos em comunidades, Alice, ao lado de Leonie, atuou na diocese de Morón, ensinando catecismo a jovens com síndrome de Down, dentre os quais, o filho de um oficial do exército argentino, o então coronel Jorge Rafael Videla. Segundo depoimento de irmã Manoela ${ }^{10}$, a primeira experiência de Alice com populações carentes, nas regiões periféricas de Buenos Aires, ocorreu em 1969, com incentivo do bispo de Morón, que constatou a ausência de religiosas nestes espaços. Nesta primeira experiência, irmã Marie Catherine, ou Cathy (nome congregacional de Alice), e a irmã Montserrat dividiam uma peça de 2,7 m x 3,0 m na localidade de Villa Lugano, a uma hora de Móron, e passavam pelas mesmas dificuldades daqueles que viviam na localidade, trabalhando como eles e ajudando no que fosse possível. Tal experiência durou cinco anos, e aos poucos foi-se redefinindo a concepção de vida cristã para Alice Domon, como observado em sua correspondência (WELTYDOMON, 2011).

Em 1974, irmã Alice toma conhecimento dos trabalhos desenvolvidos por religiosos e religiosas na região de Perugorria onde, auxiliados pelo bispo de Goya, ocorriam as primeiras reuniões de ligas agrárias, nas quais se falava a respeito da dignidade humana, preços justos do trabalho, direitos dos trabalhadores e educação para crianças. Deixa então seu trabalho em Villa Lugano por considerar que seria mais útil ao lado dos camponeses de Perugorria. Lá, trabalha no campo, auxiliando as famílias que contavam com menos braços para a função e, de acordo com uma carta enviada a uma amiga na

\footnotetext{
${ }^{10}$ Pseudônimo utilizado por Carlos Gabetta no livro "Le Diable dans le soleil".

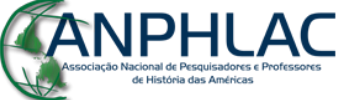

Revista Eletrônica da ANPHLAC, ISSN 1679-1061, №. 18, p. 139-161, jan./jul. 2015. http://revista.anphlac.org.br/
} 
França, se posiciona a favor da necessidade de efetivas mudanças sociais: "Você adivinha que o nosso compromisso neste mundo explorado é tomar partido com eles contra o explorador até às últimas consequências" (WELTY-DOMON, 2011, p. 33). Alice se instala ao lado dos campesinos e começa a acompanhar as reuniões das ligas, as quais serão posteriormente proibidas pelo governo devido a seu caráter subversivo.

Após breve viagem à França em 1975, por ocasião de uma assembleia geral da Congregação, Alice Domon retorna decidida a continuar seu trabalho ao lado dos campesinos, instalando-se na casa de um delegado das ligas agrárias que, naquele momento, encontrava-se detido em Resistencia. ${ }^{11}$

Aos poucos, segundo a narrativa de Arlette Welty-Domon (2011, p. 46-47) baseada nas cartas de Alice enviadas a seus familiares, o trabalho das irmãs começou a chamar atenção das autoridades:

\begin{abstract}
Nossa vida em Perugorria se torna terrível, a perseguição aumenta, eu não sei o quão longe irá. Parece realmente uma guerra declarada. É um pouco geral no país e mais acentuada em alguns pontos, como o nosso. São ataques indiretos, pela fala até agora, ameaças aos nossos amigos, etc, etc. Especialmente o prefeito e os outros estão fazendo todo o possível para afastar as pessoas da nossa Comunidade de trabalho, e nós sabemos que isto se decide em outro nível. Você tem, talvez, ecos do que está acontecendo com outros padres e religiosas. Eu não posso dizer que isto me angustia; estou, ao contrário, bastante tranquila, pois estou convencida de estar no caminho certo e que vale a pena dar a vida se necessário, solidária a todos aqueles que sofrem injustamente pela mesma causa. Mesmo se isso parece uma perseguição religiosa, sabemos que são os simples interesses e poderes de um mundo que se defende dos pobres e da justiça. ${ }^{12}$
\end{abstract}

Pelo teor da carta, podemos perceber que a irmã Alice tinha consciência dos riscos que corria em razão de sua opção que, naquele momento, transcendia as fronteiras do religioso, imiscuindo-se a práticas políticas e sociais. Neste sentido, são significativos os acontecimentos de 29 de junho de 1976, dia da festa de São Pedro. Durante a procissão,

\footnotetext{
${ }^{11}$ Cidade argentina, capital da província de Chaco.

12 "Notre vie à Perugorria devient terrible, la persécution s'amplifie, je ne sais pas jusqu'où cela ira. Cela ressemble vraiment à une guerre déclarée. C'est un peu général dans le pays et plus marqué dans certains points dont le nôtre. Ce sont des attaques indirectes, par la langue jusqu'à maintenant, des menaces auprès de nos amis, etc, etc. Spécialement le maire et autres font tout leur possible pour éloigner les gens de notre Communauté de travail, et nous savons bien que cela se joue depuis un autre niveau. Vous aurez peut-être des échos de ce qui se passe avec d'autres prêtres et religieuses. Je ne pas dire que cela m'angoisse; je suis au contraire bien tranquille, puisque je suis convaincue d'être dans le droit chemin et que cela vaut la peine de donner sa vie si nécessaire, solidaires de tous ceux qui souffrent injustement pour la même cause. Même si cela ressemble à une persécution religieuse, nous savons bien que ce sont les simples intérêts et pouvoir d'un monde qui se défend des pauvres et de la justice." (Tradução nossa)
}

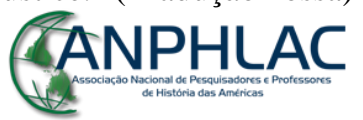

Revista Eletrônica da ANPHLAC, ISSN 1679-1061, №. 18, p. 139-161, jan./jul. 2015. http://revista.anphlac.org.br/ 
um comissário aproximou-se do cura para lhe transmitir a proibição de entoar o popular hino a São Pedro, julgado subversivo naquele momento. Antes porém de receber a proibição, irmã Alice iniciou os cantos, sendo imediatamente cerceada pelo comissário. A multidão continuou a cantar, alheia aos desentendimentos. Como forma de remediar a situação, ficou a cargo de irmã Alice ressoar uma música militar, mas, em vez disto, a irmã aproveitou o microfone para anunciar em alto e bom som que "o senhor comissário nos proibiu de cantar o hino a São Pedro" (WELTY-DOMON, 2011, p. 49).

O ano de 1976 marcou também o engajamento de Alice no Movimento Ecumênico pelos Direitos Humanos - MEDH - pelo qual entraria, algum tempo depois, em contato com as Mães da Praça de Maio. Em 8 de dezembro de 1977, na Igreja Santa Cruz, Alice participava, ao lado de mães e simpatizantes do movimento, de uma reunião destinada a arrecadar fundos para a publicação em jornais de uma lista com o nome de desaparecidos. Em torno das 17 h, vários carros estacionaram em frente à Igreja, e homens vestindo trajes civis, porém armados, precipitaram-se sobre aqueles que ali estavam, levando-os em custódia. Entre os presos estavam Azucena Villaflor, uma das fundadoras do movimento, e Alice Domon.

Dois dias após o desaparecimento de Alice, Léonie Duquet é presa em sua casa. A prisão de Léonie causou espanto; afinal, diferentemente de Alice, não costumava demonstrar publicamente posicionamentos políticos. Segundo depoimento de Yvonne Pierron, irmã da mesma Congregação, Léonie foi vítima de sua proximidade com Alice Domon. É preciso lembrar que Léonie Duquet, ainda que tenha dedicado grande parte de seu tempo ao trabalho catequético em colégios religiosos, também teve experiências de inserção a grupos campesinos e indígenas, conhecendo dessa forma realidades bastante distintas. Já em 1972 encontramos, em uma de suas cartas, posicionamentos bastante claros a respeito dos sentidos que atribuía a sua vida religiosa: "[...] aqui são os oprimidos que reagem e querem se libertar. Não podemos ficar indiferentes também devemos nos comprometer (engajar) com o povo. Isso não significa violência (mas) mudança das estruturas no governo tanto no ponto de vista político, econômico e social" (2011, p. 73).

Alice e Léonie não eram exceções no que diz respeito ao envolvimento de religiosas com questões políticas e sociais. A irmã Yvonne Pierron, que também atuava ao lado de campesinos, tal qual Alice, conta em Missionaire sous la Dictature que, após uma

\section{GANPHLAC}

Revista Eletrônica da ANPHLAC, ISSN 1679-1061, №. 18, p. 139-161, jan./jul. 2015. http://revista.anphlac.org.br/ 
série de ocasiões em que conseguiu - com o auxílio de muitos, inclusive Alice Domon escapar de buscas policiais, recebeu em 1977, logo após o desaparecimento de Alice e Léonie, um comunicado bastante direto da embaixada francesa: "Irmã Pierron ou você deixa a Argentina ou você arrisca sua vida" (PIERRON, 2007, p.101). Perante a ameaça real de encarceramento, irmã Yvonne consegue deixar a Argentina e evitar destino similar ao das companheiras de congregação.

Após o dia 10 de dezembro, com o desaparecimento das religiosas Alice e Léonie, outras irmãs da congregação, como Montserrat, e padres, como Charles Plancot, iniciaram verdadeira romaria em busca de informações sobre o paradeiro das freiras. As várias negativas a respeito de seu paradeiro geraram uma verdadeira indisposição diplomática, conforme podemos observar nas reportagens publicadas pela Folha de São Paulo. Em 18 de dezembro de 1977, o jornal publica pela primeira vez uma nota sugerindo não o paradeiro, mas os responsáveis pelo sequestro das irmãs. A reportagem "Montoneros assumem sequestro das duas freiras" anunciava que "a organização clandestina de esquerda enviou ontem pela manhã um comunicado reivindicando o sequestro à agência France Press de Buenos Aires" (Folha de São Paulo, 18/12/1977, p.21). Além do comunicado, a agência recebeu uma foto das religiosas diante da insígnia da organização e uma carta de autoria de Alice Domon. Tais documentos, segundo a reportagem da Folha, viriam a confirmar a versão divulgada pelo governo argentino, segundo o qual "os responsáveis pelo desaparecimento das duas religiosas seriam grupos subversivos."

Figura 1: Foto montagem enviada à agência France Press

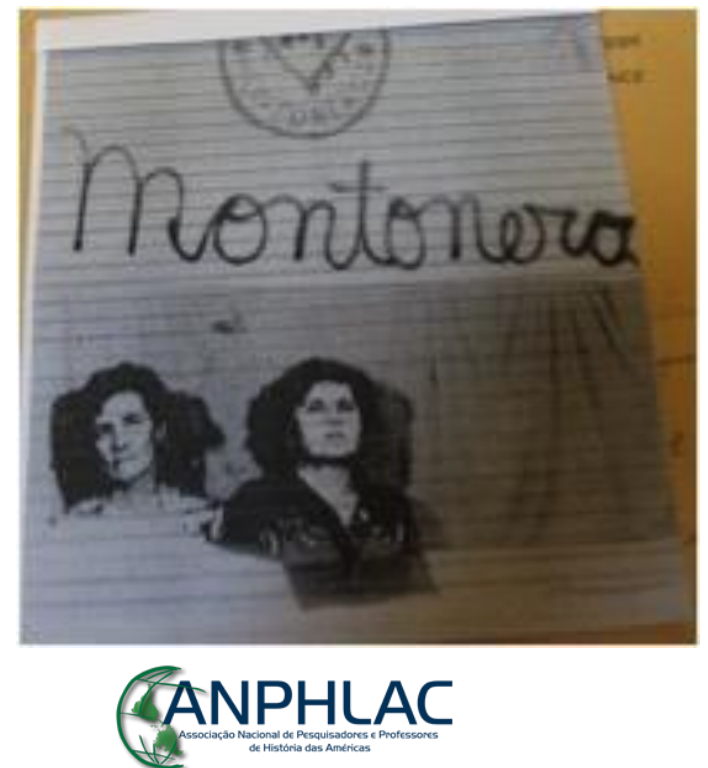

Revista Eletrônica da ANPHLAC, ISSN 1679-1061, №. 18, p. 139-161, jan./jul. 2015. http://revista.anphlac.org.br/ 
Fonte: Arquivo da Conférence des Évèques de France (1977)

No dia seguinte, porém, a nota "Não há presos políticos na Argentina, diz Videla", traz declarações do presidente argentino, segundo o qual, em seu país, não havia presos políticos, e sim "delinquentes subversivos", e que estes não chegavam ao número de "quatro mil". Logo ao fim da reportagem, um subtítulo chama-nos atenção: "Desmentido dos montoneros." Em dois parágrafos encontramos a informação de que, em Paris, um porta-voz dos montoneros havia desmentido "categórica e inequivocamente as caluniosas afirmações atribuindo a seus quadros o sequestro de duas freiras" (Folha de São Paulo, 19/12/1977, p. 05).

A leitura da carta de Alice Domon apresenta, para aqueles que a conheciam, indícios de que fora uma escrita ditada. Esta foi a afirmação publicada em 4 de fevereiro de 1978 pelo periódico France Soir, em uma reportagem bastante sugestiva sob o título "Irmã Alice conseguiu enviar uma mensagem secreta" (FRANCE SOIR, 04/02/1978). De acordo com o periódico francês, a irmã Alice foi extremamente perspicaz no momento em que lhe foi solicitado escrever uma carta ao padre Jean Guyot, superior das Irmãs das Missões Estrangeiras, na qual deveria falar sobre sua situação e negociar a libertação de presos políticos. Irmã Alice, francesa escrevendo para um padre francês, utiliza na carta termos em espanhol que indicariam, por não fazerem sentido em francês, uma escrita a contragosto. Além disso, lança mão de determinadas construções e palavras que sugeriam a real identidade de seus sequestradores. Citam a passagem: "(aqui) Ici, je suis bien de salud et dans une situation de prisonnière (par un groupe dissident du governement actuel de R. Videla)." A escolha do termo "dissident" (dissidente), segundo o periódico francês, era bastante sagaz, afinal possibilitava interpretações e sugeria que seus raptores, de alguma maneira, participavam do governo de Videla.

Após algumas reportagens analisando aspectos da situação política argentina e citando o caso das irmãs como exemplar da repressão, a Folha de São Paulo volta a falar exclusivamente sobre o caso em 08 de janeiro de 1978, para anunciar, porém, "Nenhuma notícia sobre as freiras." A pequena nota destinava-se apenas a marcar a passagem de um mês do desaparecimento que, conforme um correspondente de Buenos Aires, continuava envolto em mistério (Folha de São Paulo, 08/01/1978, p. 21).

\section{GANPHLAC}

Revista Eletrônica da ANPHLAC, ISSN 1679-1061, №. 18, p. 139-161, jan./jul. 2015. http://revista.anphlac.org.br/ 
As primeiras acusações diretas ao governo argentino aparecem na Folha de São Paulo ainda em janeiro de 1978, quando o ex-senador argentino Hipólito Solari Yrigoyen afirma categoricamente que o governo argentino, em relação ao sequestro das religiosas, agia exatamente da mesma forma como quando ele foi sequestrado em agosto de 1976: mentindo (Folha de São Paulo, 17/01/1978, p.10).

As afirmações de Yrigoyen foram efetivamente confirmadas. Em 05 de setembro de 1985, uma reportagem francesa produzida pelo canal Antenne 2 foi ao ar apresentando o testemunho de um antigo torturador da ditadura argentina que assumiu haver conhecido as irmãs francesas e acompanhado com bastante proximidade o desfecho de sua trajetória. $\mathrm{O}$ depoente apresenta em detalhes aquilo que, afirma, teria acontecido às freiras francesas a partir do momento em que foram presas e levadas à Escola de Mecânica da Marinha Argentina - ESMA. Após declarar que seu compromisso em ceder a entrevista era com a verdade, conta que, logo depois de chegarem à ESMA, as freiras foram despidas, amarradas, torturadas com choques elétricos e sexualmente violadas. Após dois meses de torturas cotidianas, foram deslocadas ao $3^{\circ}$ Batalhão de Infantaria da Marinha, em La Plata. Lá foram novamente submetidas a sevícias e ao que o depoente descreve como uma violência desmedida por parte do Capitão Alfredo Astiz. Na tentativa de explicar tamanho furor, o depoente afirma que isso acontecia talvez por serem francesas, talvez por serem religiosas.

Dias depois foram novamente transferidas para um campo chamado Vesúvio, onde ficaram cerca de 15 dias. Nova transferência levou-as ao Hospital Militar onde deveriam se recuperar para novos interrogatórios e novas torturas. Alguns dias depois, no entanto, vieram a falecer devido ao esfacelamento de suas forças. Foram enterradas anonimamente em uma vala comum, nas proximidades de um Centro de Instrução e Formação da Marinha argentina.

Apesar de abundantemente detalhado, o depoimento do torturador entra em conflito com informações divulgadas em 2011, a respeito da apuração do que ficou conhecido como os "voos da morte". Em 11 de maio de 2011, o diário argentino Página/12 noticia a prisão e depoimento de cinco supostos envolvidos em voos da morte, que consistiam em recolher presos e atirá-los ao vazio. Segundo investigações realizadas pela Procuradoria Geral da República, Alice Domon e Léonie Duquet teriam sido vítimas de um

\section{GANPHLAC}

Revista Eletrônica da ANPHLAC, ISSN 1679-1061, №. 18, p. 139-161, jan./jul. 2015. http://revista.anphlac.org.br/ 
desses voos. Conforme a reportagem, após a verificação de 2.758 planilhas de quatro aviões Skyvan, foi identificado, entre outros, o voo da aeronave PA-51, registrado em 14 de dezembro de 1977, que teria deixado o aeroparque Jorge Newbery às 21h30, voado durante 3 horas e 10 minutos, e retornado sem passageiros, conforme os registros. Horas antes haviam sido fotografadas as irmãs Alice e Léonie, cujos corpos apareceram dias mais tarde nas praias de San Bernardo (p. 12, 11/05/2011). Das praias de San Bernardo, cogitase, os corpos foram levados e enterrados em valas comuns. Em 2005, vários jornais noticiaram o reconhecimento, por exames de DNA, do corpo de Léonie Duquet, encontrado nas imediações de Buenos Aires. O corpo de Alice Domon segue desaparecido.

\section{Considerações finais}

As histórias de Léonie Duquet e Alice Domon foram amplamente divulgadas. Uma conjunção de fatores determinou o caráter extraordinário do caso, garantindo-lhe páginas de jornais e atenção por parte de órgãos do governo, das Igrejas e daqueles que se deparavam com as narrativas sobre freiras presas acusadas de subversão. A participação de religiosas em movimentos políticos, sociais e de resistência à ditadura, armada ou cotidiana, não pode, porém, ser reduzida unicamente aos casos midiatizados. Assim como o caso de Alice e Léonie, durante nossas pesquisas deparamo-nos com várias histórias de religiosas que se mobilizaram e agiram de diferentes maneiras para contestar realidades opressoras, promovidas pelos regimes ditatoriais. Nosso interesse com o presente artigo é mostrar que a participação e envolvimento das religiosas transcendem as ínfimas quantificações às quais temos acesso. Tais números são geralmente baseados em dados oficiais e, portanto, dizem respeito àqueles que, institucionalmente, atuavam em nome da Igreja. O papel assumido pelas freiras que se voltaram à resistência era, na maioria das vezes, velado. Elas atuavam por meio de movimentos sociais, grupos de conscientização, acolhiam perseguidos, escondiam armas e materiais considerados subversivos em seus colégios e conventos, entre outras práticas que, certamente, não seriam tornadas públicas. A participação das freiras precisa ser observada a partir das especificidades concernentes àquelas que se dedicavam à vida religiosa e aos espaços por elas ocupados. Especialmente a partir dos anos 60, a inclusão de religiosas em movimentos de cunho político-social está

\section{CANPHLAC}

Revista Eletrônica da ANPHLAC, ISSN 1679-1061, №. 18, p. 139-161, jan./jul. 2015. http://revista.anphlac.org.br/ 
imediatamente ligada às modificações institucionais da própria Igreja, que possibilitava maiores aproximações com comunidades desassistidas e com uma realidade que contrariava até mesmo preceitos de dignidade cristã. A repressão, a violência e a miséria sensibilizavam homens e mulheres que, a partir de diferentes espaços sociais, utilizavam as estratégias às quais tinham acesso para lutar contra uma situação de opressão. No caso das freiras, suas histórias permanecem ainda envoltas em silêncio, seja por motivos institucionais ou por opções pessoais. Essas histórias são imprescindíveis para uma compreensão ampliada da vida religiosa feminina e suas relações com as ditaduras militares na América Latina durante a segunda metade do século XX.

\section{GANPHLAC}

Revista Eletrônica da ANPHLAC, ISSN 1679-1061, №. 18, p. 139-161, jan./jul. 2015. http://revista.anphlac.org.br/ 


\section{Fontes:}

\section{a) Diversos}

ALVEAR, Bispo Enrique (et alli.) Comuniqué au Vatican. Riobamba, 13/ 08/ 1976. BDIC - Bibliothèque de Documentation Internationale Contemporaine. Fundo Fdelta2118.

Commission Tiers-monde de l'Église Catholique. Une lutte systématique contre l'Eglise d'Amérique Latine. BDIC - Bibliothèque de Documentation Internationale Contemporaine. Fundo Dial. Nanterre, França.

MARTINEZ, Diego. Un aterrizaje forzoso para cinco pilotos. Página/ 12. Argentina. 11 mai. 2011. El País. Disponível em http://www.pagina12.com.ar/diario/elpais/1-1679582011-05-11.html. Acesso em 22/07/ 2014.

RESISTANCE. Produção de Michel Thoulouze. Paris. Antenne 2. 1985. Disponível em http:// www.ina.fr /video/CAB99020291/disparitions-en-argentine-video.html. Acesso em 12/08/2013.

\section{b) Jornais:}

Acusação nos EUA: Freira é que armava terrorista na Guatemala. Diário de Notícias. Rio de Janeiro. 23 jan. 1968. p.09.

Deputado morto investigava ação do governo argentino. Folha de São Paulo. São Paulo. 02 ago. 1974. 1o. Caderno. p. 05.

Documento denuncia agressões contra a Igreja. Folha de São Paulo. Primeiro Caderno. 23/.01/1979, p. 5.

França quer saber paradeiro das freiras. Folha de São Paulo. São Paulo. 15 dez. 197710. Caderno.

Freira é quem conseguia armas para guerrilheiros. Diário de Notícias. Rio de Janeiro. 23 jan. 1968. Capa.

Governo argentino promete anistia. Folha de São Paulo. São Paulo. 14 dez. 1977. $1^{\circ}$. Caderno, p. 09.

Montoneros assumem sequestro das duas freiras. Folha de São Paulo. São Paulo. 18 dez. 1977, p. 21.

Nenhuma notícia sobre as freiras. Folha de São Paulo. São Paulo. 08 jan., 1978, p. 21.

\section{GANPHLAC}

Revista Eletrônica da ANPHLAC, ISSN 1679-1061, №. 18, p. 139-161, jan./jul. 2015. http://revista.anphlac.org.br/ 
Não há presos políticos na Argentina, diz Videla. Folha de São Paulo. São Paulo. 19 dez. 1977, p. 05.

Soeur Alice a réussi à envoyer un message secret. France Soir. France. 04 fev. 1978. Arquivo da Conférence des Évèques de France. Dossiê: Argentine: L'Église persecutée.

Yrigoyen acusa polícia argentina. Folha de São Paulo. São Paulo. 17 jan., 1978, p.10.

\section{Bibliografia}

BLOCH, Marc apud BARROS, José Assumpção de. História Comparada: da contribuição de Marc Bloch à constituição de um moderno campo historiográfico. História social. N.13, Campinas, 2007.

BROLHANI, Cristina Aparecida. A atuação de mulheres em comunidades de base católica. Anais do II Seminário Internacional Educação Intercultural, Gênero e Movimentos Sociais: Identidade, Diferença e Mediações. 2003. Disponível em http://www.rizoma.ufsc.br/pdfs/517-of8c-st2.pdf. Acesso em 14 de maio de 2012.

CATOGGIO, María Soledad. Cambio de hábito: trayectorias de religiosas durante la última dictatura militar argentina. Latin America Research Rewiew. vol. 45. n.02. 2010.

FOUCAULT, Michel. História da sexualidade: a vontade de saber. Rio de Janeiro: Graal, 1988.

GABETTA, Carlos. Le Diable dans le soleil. Paris: Atelier Marcel Jullian, 1979.

KEDAR, Benjamin Z. Outlines fo Comparative History proposed by practicing historians. In: KEDAR, Benjamin Z. (ed. ) Explorations in Comparative History. Jerusalem: The Hebrew University Magnes Press, 2009.

LOWY, Michael. A guerra dos deuses: religião e política na América Latina. Petrópolis: Vozes, 2000

MIGNONE, Emilio. Iglesia Y dictadura: el papel de la Iglesia a la luz de sus relaciones con el régimen militar.Buenos Aires: Colihue, 2006. NUNES, Maria José Rosado. Freiras no Brasil. In DEL PRIORE, Mary (org). História das mulheres no Brasil. São Paulo: Contexto, 1997.

PEDRO, Joana Maria e WOLFF, Cristina Scheibe. A pesquisa sobre Gênero, feminismos e ditaduras no Cone Sul: um relato de viagens e algumas reflexões. In: PEDRO, Joana Maria; WOLFF, Cristina Scheibe; VEIGA, Ana Maria (orgs). Resistências, gênero e feminismos contra as ditaduras no Cone Sul. Florianópolis: Ed. Mulheres, 2011.

PIERRON, Yvonne. Missionaire sous la dictature. Paris: Éditions du seuil, 2007.

SEMELIN, Jacques. Sans armes face à Hitler. Paris: Les Arènes, 2013.

\section{GANPHLAC}

Revista Eletrônica da ANPHLAC, ISSN 1679-1061, №. 18, p. 139-161, jan./jul. 2015. http://revista.anphlac.org.br/ 
SENA, Priscila C. de, MORETTI, Vivian B. Fé e relações de gênero nas esquerdas cristãs: Brasil e Chile no contexto das ditaduras latino-americanas. In: PEDRO, Joana M., WOLFF, Cristina S., VEIGA, Ana M. Resistências, gênero e feminismos contra as ditaduras no Cone Sul. Florianópolis: Editora Mulheres, 2011.

SERBIN, Kenneth P. Padres, celibato e conflito social: uma história da Igreja Católica no Brasil. São Paulo: Companhia das Letras, 2008.

TOURIS, Claudia. Catolicismo y cultura politica en la Argentina. La "constelación tercermundista" (1955-1976). 2012. 463f. Tese (Doutorado em História). Facultad de Filosofia y Letras. Universidad de Buenos Aires.

TOURIS, Claudia. Entre Marianne y Maria: Los tayectos de las religiosas tercermundistas en la Argentina. In: ANDÚJAR, Andrea (et all.) De minifaldas, militancias y revoluciones: Exploraciones sobre los 70 en la Argentina. Buenos Aires: Luxemburg, 2009.

WELTY-DOMON, Arlette. Soleil de Justice: la passion de soeur Alice. Montpellier: Les éditions de la Campagnette, 2011.

WERNER, Michael; ZIMMERMANN, Bénédicte. Penser l'histoire croisée: entre empirie et reflexivité. Annales. Histoire, Sciences Sociales. 2003/1, ano 58.

\section{GANPHLAC}

Revista Eletrônica da ANPHLAC, ISSN 1679-1061, №. 18, p. 139-161, jan./jul. 2015. http://revista.anphlac.org.br/ 